\title{
Tailored Spider Silk: The Future Solution to Biomaterials
}

\author{
Abdalla S*, Obaid A, Al-Marzouki F and Bahabri F \\ Department of Physics, Faculty of Science, King Abdulaziz University Jeddah, P.O. Box 80203, Jeddah 21589, Saudi Arabia
}

Some insects have evolved over millions of years to produce fantastic biomaterials and sometimes they exceed manufactured materials with extraordinary characteristics. One of these biomaterials is spider silk (SS) that contains large proteins. SS-fibers are as tough as steel and some SS-fibers have elasticity near caoutchouc $[1,2]$. When one combines their fantastic characteristics, SS show double or even triple toughness of manufactured-fibers such as Kevlar or Nylon. In addition, SS shows (I) passive-inflammation, (II) it is inactive for allergic reactions, (III) it is completely biodegradable-material, (IV) it is hypoallergenic and (v) it is antimicrobial at ambient conditions [3]. These properties present SS as a future biomaterial. Therefore, this article draws attention to the importance of SS for different applications and shows the structurefunction close relation between the highly repetitive (HR) SS-proteins with the corresponding conformational alteration to strings from the initial solution form. This information is decisive because one has to know the mechanism (s) how this alteration occurs and to understand the intrinsic characteristics of SS-fibers. In addition, it is important to know the highly sophisticated assembly techniques of silk proteins. There are different types of SS-webs (SSWs); among the most famous is the orb-web (OW) that contains different sorts of SS [4]. In general, components of orb-web are made of very robust SS. The major ampullate (MA) glands produce two different types of protein. As a particular case, MA-SS can be utilized as roping thread that can help to escape predators. For example, the catch winding of an OW contains strings with one sort of protein that is generated in the gland of spider as flagella form (Flag). Flag-SS has high degree of elasticity about three hundred percent which is completely enough to squander the internal energy of prey. The web scaffolding joint-points are well welded to external supports (such as trees for example) through advanced silk binder contain special proteins created in the insect $[5,6]$.

\section{The Structure of Spider Silk}

Essentially, SS contains special proteins, which consists of huge amounts of hydrophobic-amino acids (for example glycine and/or alanine) and nonpolar amino acids, and there is no tryptophan [7]. As it is illustrated in Figure 1A, SS-protein exhibits a chemical composition very close to amino acid with highly repetitive amino acid sequences that composes about $90 \%$ of the entire SS-protein (Figure 1B). In addition, there are short polypeptide stretches having nearly 10-50 amino acids. Each repeat of them has functional characters leading to the wonderful mechanical properties of SS-threads. In particular, MASS contains up to four typical oligopeptide motifs that suffers different repetition as $\{\mathrm{i}\}$ GGX (X=A, S or Y) $\{\mathrm{ii}\}(\mathrm{GA}) \mathrm{n} /(\mathrm{A}) \mathrm{n},\{\mathrm{iii}\}$ GPGGX/ GPGQQ and \{iv\} regulated-space successions that have charges on their amino acids (Figure 1C) [5,6]. Scheibel et al. [8] have shown that some repetitive domains and some non-repetitive domains are present at the ends of protein's series [8]. The non-repetitive termini control the processes of the proteins assembly of SS-protein into fibers [9]. Rising et al. have shown that the regions comprise some hundreds of amino acids and they reported that well located and defined tripartiteand tripartite-forms are present in sol [9].

Several authors $[10,11]$ reported that these domains result in some inter-molecular disulfide bonds, which, under oxidizing conditions, can stabilize dimers and multimers. As a consequence, several papers
$[10,11]$ reported that these domains can lunch and appoint texture of SS-proteins $[10,11]$.

\section{The Texture of Spider Silk}

Dicko et al. [12] have shown that assembly process cannot initiate with globular folded protein monomers. It can start essentially with unfolded proteins at very high concentrations [12]. In order to keep and maintain high concentrations of protein, Hijirida et al. [13] have reported that several mechanisms should be necessary to keep these high concentrations as high as up to fifty percent w/v [13] inside the insect. This includes lyotropic liquid crystallinity, glycosylation of the external superficies of the tucked SS-proteins and period split persuade by a polyol or by a phospholipid surfactant. SS transforms to texture when starting the spinning duct and the silk form turns $\mathrm{H}_{2} \mathrm{O}$-resistable [14]. Figure 2 illustrates this situation. Different conditions such as $\mathrm{pH}$, ionic concentration, water content, etc. should be controlled to get good and efficient assembly. This demands bi-stable bending processes of the concerned protein and firm control of the surrounding states.

\section{Mimicking Nature-Recombinant Spider Silk}

Authors have used different techniques for recombinantly producing SS-proteins, because recombinant production of ample quantities of SS-proteins is crucial to clarify and to understand their assembly behavior and their structure [15-18]. It is very complicated to characterize the exact CDNA successions of a SS-gene because of its highly repetitive character of individual SS-molecules. The conversion of premier or fractioned silk genes to steward of some microorganism bacteria can lead to get recombinant SS-proteins. However, bacteria are not the suitable host for this task because the genes have large size [19]. In addition, when one compares the various codon uses of spiders with bacteria, one can note that the recombinant creation of SS-proteins in bacteria is more hard and difficult [20].

\section{Artificial Spinning of Spider Silk}

It is worth pointing out that researchers will be able, in the near future, to understand and test the texture of SS-threads in a functional in vitro weaving technique due to the availability of recombinant SSproteins. Figure 2 illustrates that the produced SS-string looks like natural silk in its mechanical properties, fine-, and chemical-structure [21]. In order to adapt the developed spinning machinery of spiders, different parameters should be considered:

*Corresponding author: Soliman Abdalla, Department of Physics, Faculty of Science, King Abdulaziz University Jeddah, P.O. Box 80203, Jeddah 21589, Saudi Arabia, Tel: +966-58-234-3822; E-mail: smabdullah@kau.edu.sa

Received September 12, 2017; Accepted September 20, 2017; Published September 30, 2017

Citation: Abdalla S, Obaid A, Al-Marzouki F, Bahabri F (2017) Tailored Spider Silk The Future Solution to Biomaterials. J Material Sci Eng 6: 375. doi: 10.4172/21690022.1000375

Copyright: $\odot 2017$ Abdalla S, et al. This is an open-access article distributed under the terms of the Creative Commons Attribution License, which permits unrestricted use, distribution, and reproduction in any medium, provided the original author and source are credited. 


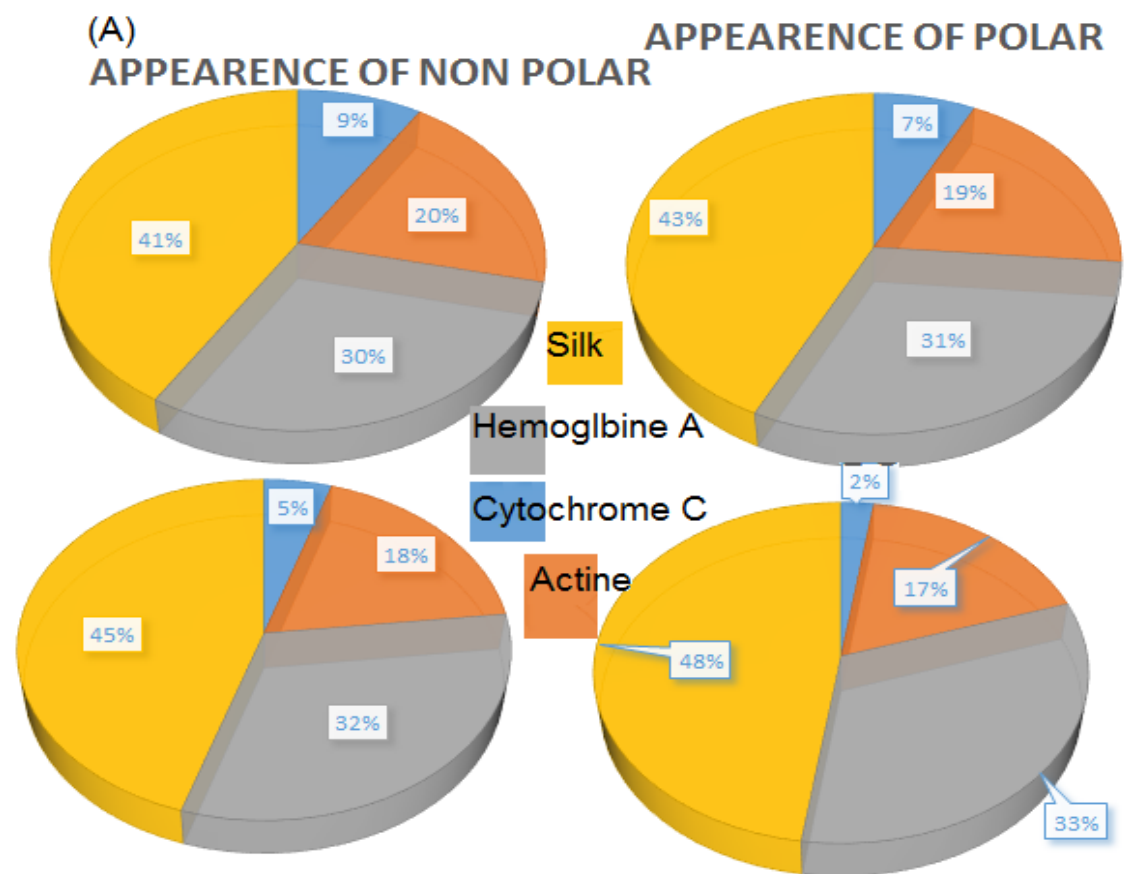

APPEARENCE OF AROMATIC APPEARENCE OF CHRGED

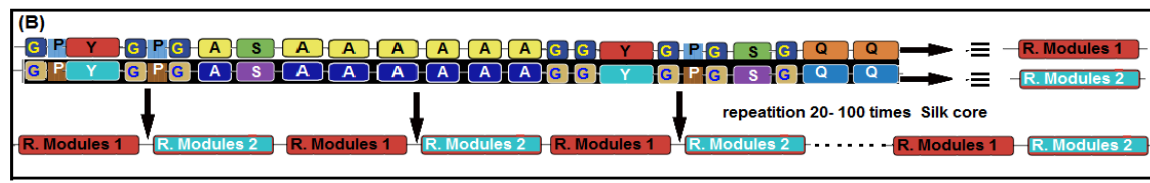

\begin{tabular}{|c|c|c|c|c|}
\hline \multicolumn{2}{|c|}{ (C) protein origin } & $\begin{array}{l}\text { amino acid } \\
\text { sequence }\end{array}$ & $\begin{array}{l}\text { putative } \\
\text { structure }\end{array}$ & property \\
\hline 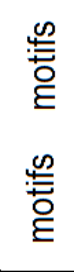 & $\begin{array}{c}\text { MA } \\
\text { MA } \\
\text { Flag } \\
\text { MA/Flag } \\
\text { Flag }\end{array}$ & $\begin{array}{c}(G A)_{n} / A_{n} \\
(G P G Q Q) \\
(G P G G X) \\
(G G X) \\
\text { spacer }\end{array}$ & $\begin{array}{l}\text { Beta-sheet } \\
\text { Beta-spiral } \\
\text { Beta-spiral } \\
3_{10} \text { helix } \\
\text { unstructured }\end{array}$ & $\begin{array}{l}\text { strong } \\
\text { elastic } \\
\text { elastic } \\
\text { elastic } \\
\text { elastic }\end{array}$ \\
\hline : & $\begin{array}{l}\text { MA/Flag } \\
\text { MA/Flag }\end{array}$ & $\begin{array}{l}\mathrm{NR}_{\mathrm{N}} \text {-domain } \\
\mathrm{NR}_{\mathrm{C}} \text {-domain }\end{array}$ & $\begin{array}{l}\text { helical } \\
\text { helical }\end{array}$ & $\begin{array}{c}\text { signal } \\
\text { sequence } \\
\text { and } \\
\text { unknown } \\
\text { assembly }\end{array}$ \\
\hline
\end{tabular}

Figure 1: (A) Comparing three well-known proteins amino acids to SS. (B) Proposed pattern of the constructing of a major ambulate (MA) SS-protein (C) Amino acid motifs of SS-proteins. Amino acids present in MA and Flag silk are restored with their delusive composition and their influence on the ultimate characteristics of the string.

First, in addition to the phase separation process in the spinning duct and the protein composition of the spinning dope, one should consider several mechanical parameters silk assembly. For example, spiders, in nature, use the weight in case of curling and draw the thread with the hind legs out of the spinning wart [22]. In laboratory, scientists copied this drawing process by forced silking of captive spiders. It is worth noting that researcher have reported important differences in thread diameters, ductility and resilience depending on temperature and spinning speed [23]. Several papers reported that SS obtained at higher groggy quickness have a little bit more output. However, they are less extendable and more feeble than SS interweaved at reduced speeds. In order to weave recombinant spider silk proteins for scientific objectives, one should consider some aspects: First, researchers can utilize wet-spinning processes [24] and they can use silicon tinnyspinnerets (on microscale) some meters of insect or SS-string. These processes will lead to wet-spun silks with radius with ten times more than the radius of normal SS, which lowers the mechanical properties. Researches can use special posts-pinning techniques that can lead to silks having better radius [25]. In all cases, so far, the mechanical characteristics gained by synthetic weaving techniques are by far thinner than that of normal SS [26]. 


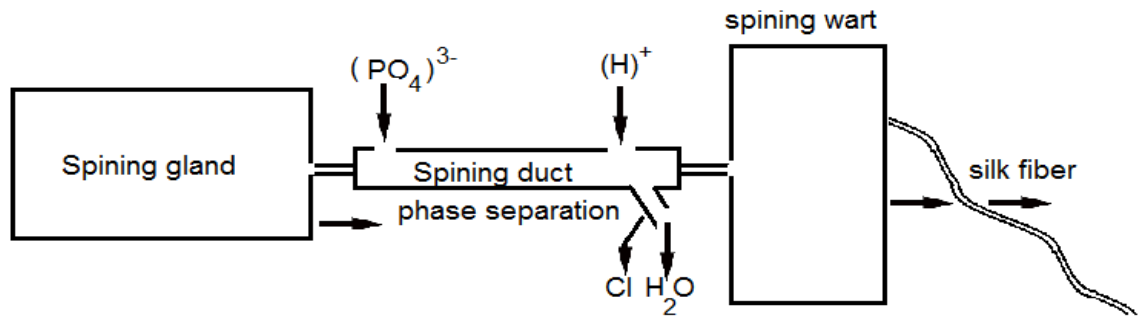

Figure 2: The spinning gland secretes and stores highly concentrated SS-protein solution. Then, the phase separation process occurs if the solution will be directed through a narrow ion exchange.

SS-proteins, in nature, are exclusively transform into SS-threads. It is possible, in vitro, that SS-proteins transform in other two- or three-dimensional forms. One can notice from the images of electron microscopy different forms as: Capsule, sphere, thread and nano-fibrils, in addition to a hydrogel and a film (image) formed by recombinantly generated tailored SS-protein [27]

One can exceed nature when using SS in three dimensions. Figure 3 shows SS-protein with three dimension microscopic structures. Recently, scientists attempt to use SS-protein as biopolymer (novel biomaterial) for different applications. For example, researchers can prepare SS-films from a watered SS-sol [27]. Here, researchers can pour a solution of SS with suitable solvent such as water and let it to evaporate. Then the SS-protein textures on the surface and shape a transparent, robust diaphragm. One can tailor the thickness of films from some nanometers up to different $\mu$ m's having several mechanical and chemical properties. This can occur with good choice of temperature, solvent and surrounding conditions. Here, the produced films can give secondary and tertiary structure formation of these proteins depending on preparation conditions. Several papers [27-30] reported that SS-proteins of MA are intrinsically unfolded in aqueous solution. However, if one prepares a SS-film, the proteins rapidly will alter to a spiral arrangement and post-handling of the diaphragms with non-polar solvents such as methyl alcohol can lead to more structural rearrangements of SS-protein. This can increase the beta-sheet content dramatically [27-30]. Moreover, SS, in vitro, can further able to selfassemble into small nano-fibrils upon developing, at room temperature for some days, in potassium phosphate buffer [28-31]. One can structurally compare the obtained SS-fibrils with amyloid fibrils. Interestingly, testing the composition-function correlations of SSproteins in the near future will explain the reason of extreme toughness of SS-threads, in addition it will help to tailor and even design new polymeric biomaterials. In summary, to discover the secrets behind the extraordinary toughness of SS-threads researchers should take more deep steps to analyze the structure-function relationship of SS-proteins which will also help to tailor, engineer and design novel bio- and polymeric-materials. Moreover, the control of SS-assembly will help researches to obtain new biomaterials tailored to have characteristics under desire upon the market demand.

\section{Acknowledgements}

This project was supported by King Abdulaziz City of Science and Technology, general direction of research grants - Project No. (ARP-35-157), the author also, acknowledge with thanks the Deanship of Scientific Research, King Abdulaziz University for technical support.

\section{References}

1. Wu Y, Shah DU, Liu C, Yu Z, Liu J, et al. (2017) Bioinspired supramolecular fibers drawn from a multiphase self-assembled hydrogel. Proceedings of the National Academy of Sciences 201705380.

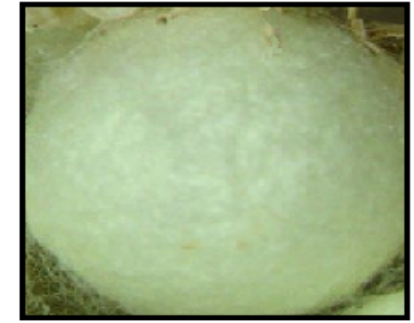

Sphere

Capsule
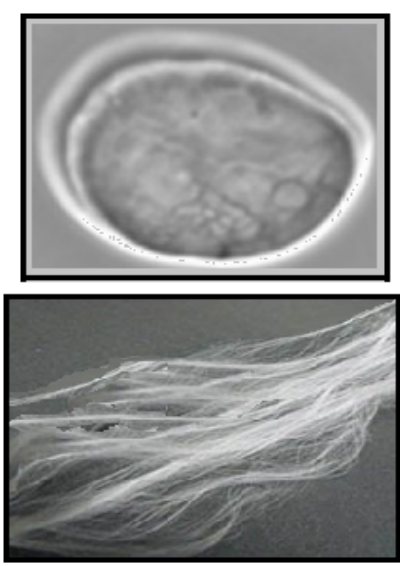

Thread

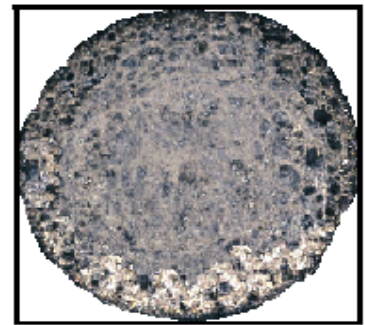

Film

Hydrogel

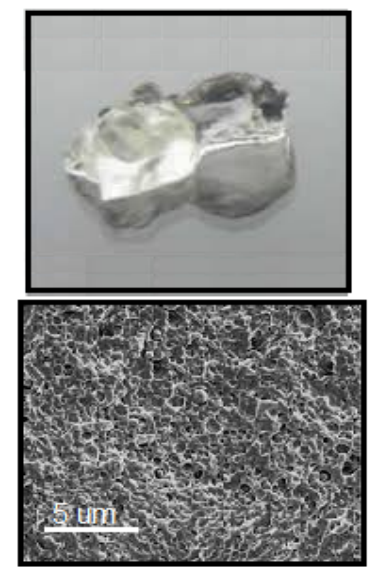

Nano-fibers Silk
Figure 3: Different imaginable (possible) forms of SS.

2. Gosline JM, Denny MW, DeMont ME (1984) Spider silk as rubber. Nature 309 551-552.

3. Harvey D, Bardelang P, Goodacre SL, Cockayne A, Thomas NR (2017) Antibiotic Spider Silk: Site-Specific Functionalization of Recombinant Spider Silk Using "Click" Chemistry. Advanced Materials 29(10).

4. Liu D, Yu L, He Y, Peng K, Liu J, et al. (2017) Peculiar torsion dynamical response of spider dragline silk. Applied Physics Letters 111: 013701.

5. Qi Y, Wang H, Wei K, Yang Y, Zheng RY, et al. (2017) A Review of Structure Construction of Silk Fibroin Biomaterials from Single Structures to Multi-Level Structures. International journal of molecular sciences 18: 237.

6. Melke J, Midha S, Ghosh S, Ito K, Hofmann S (2016) Silk fibroin as biomaterial for bone tissue engineering. Acta biomaterialia 31: 1-16.

7. Meinel L, Kaplan DL (2012) Silk constructs for delivery of musculoskeletal therapeutics. Advanced drug delivery reviews 64: 1111-1122.

8. Scheibel T (2004) Spider silks: recombinant synthesis, assembly, spinning, and engineering of synthetic proteins. Microbial cell factories 3: 14.

9. Hu X, Yuan J, Wang X, Vasanthavada K, Falick AM, et al. (2007) Analysis of 
aqueous glue coating proteins on the silk fibers of the cob weaver, Latrodectus hesperus. Biochemistry 46: 3294-3303.

10. Arzt E, Gorb S, Spolenak R (2003) From micro to nano contacts in biological attachment devices. Proceedings of the National Academy of Sciences 100: 10603-10606.

11. Townley MA, Tillinghast EK, Neefus CD (2006) Changes in composition of spider orb web sticky droplets with starvation and web removal, and synthesis of sticky droplet compounds. Journal of Experimental Biology 209: 1463-1486.

12. Dicko C, Kenney JM, Knight D, Vollrath F (2004) Transition to a $\beta$-sheet-rich structure in spidroin in vitro: the effects of $\mathrm{pH}$ and cations. Biochemistry 43 : 14080-14087.

13. Hijirida DH, Do KG, Michal C, Wong S, Zax D, et al. (1996) 13C NMR of Nephila clavipes major ampullate silk gland. Biophysical journal 71: 3442-3447.

14. Scheibel T (2004) Spider silks: recombinant synthesis, assembly, spinning, and engineering of synthetic proteins. Microbial cell factories 3: 14 .

15. Sponner A, Vater W, Rommerskirch W, Vollrath F, et al. (2005) The conserved C-termini contribute to the properties of spider silk fibroins. Biochemical and biophysical research communications 338: 897-902.

16. Sponner A, Unger E, Grosse F, Weisshart K (2004) Conserved C-termini of spidroins are secreted by the major ampullate glands and retained in the silk thread. Biomacromolecules 5: 840-845.

17. Huemmerich D, Helsen CW, Quedzuweit S, Oschmann J, Rudolph R, et al (2004) Primary structure elements of spider dragline silks and their contribution to protein solubility. Biochemistry 43: 13604-13612.

18. Vendrely C, Scheibel T (2007) Biotechnological Production of Spider-Silk Proteins Enables New Applications. Macromolecular bioscience 7: 401-409.

19. Andersson M, Jia Q, Abella A, Lee XY, Landreh M, et al. (2017) Biomimetic spinning of artificial spider silk from a chimeric minispidroin. Nature chemical biology.

20. Xu M, Lewis RV (1990) Structure of a protein superfiber: spider dragline silk. Proceedings of the National Academy of Sciences 87: 7120-7124.
21. Koh LD, Cheng Y, Teng CP, Khin YW, Loh XJ, et al. (2015) Structures, mechanical properties and applications of silk fibroin materials. Progress in Polymer Science 46: 86-110.

22. Eberhard WG (1980) The natural history and behavior of the bolas spider, Mastophora dizzydeani sp. n.(Araneae). Psyche 87: 143-170.

23. Saravanan D (2006) Spider silk-structure, properties and spinning. Journal of textile and apparel, technology and management 5: 1-20.

24. Andersson M, Jia Q, Abella A, Lee XY, Landreh M, et al. (2017) Biomimetic spinning of artificial spider silk from a chimeric minispidroin. Nature Chemical Biology.

25. Volkov V, Ferreira AV, Cavaco-Paulo A (2015) On the Routines of WildType Silk Fibroin Processing Toward Silk-Inspired Materials: A Review. Macromolecular Materials and Engineering 300: 1199-1216.

26. Zeng DM, Pan JJ, Wang Q, Liu XF, Wang H, et al. (2015) Controlling silk fibroin microspheres via molecular weight distribution. Materials Science and Engineering: C 50: 226-233.

27. Jin HJ, Kaplan DL (2003) Mechanism of silk processing in insects and spiders Nature 424: 1057

28. Cui X, Wen J, Zhao X, Chen X, Shao Z, et al. (2013) A pilot study of macrophage responses to silk fibroin particles. Journal of Biomedical Materials Research Part A 101: 1511-1517.

29. Kim MK, Lee JY, Oh H, Song DW, Kwak HW, et al. (2015) Effect of shear viscosity on the preparation of sphere-like silk fibroin microparticles by electrospraying. International Journal of Biological Macromolecules 79: 988995.

30. Lee OJ, Kim JH, Moon BM, Chao JR, Yoon J, et al. (2016) Fabrication and characterization of hydrocolloid dressing with silk fibroin nanoparticles for wound healing. Tissue Engineering and Regenerative Medicine 13: 218-226.

31. Khalid A, Mitropoulos AN, Marelli B, Simpson DA, Tran PA, et al. (2015) Fluorescent nanodiamond silk fibroin spheres: advanced nanoscale bioimaging tool. ACS Biomaterials Science \& Engineering 1: 1104-1113. 